\title{
TRANSITIONAL ISSUES DURING MIGRATION TO AN INTEGRATED DATA WAREHOUSE SYSTEM: A CASE STUDY
}

\author{
Michael J. Curran, Robert Morris University, mjcst44@mail.rmu.edu
}

\begin{abstract}
This report presents a case study analysis involving four mid-level managers (academic deans) at a for-profit university, as they experienced a transition from a silo based data management system to a fully integrated data warehouse system. The study revealed that, for these participants, major transitional issues included frustration with lack of access to data that they previously had, an increase in errors from inaccurate data, and increased alienation from the organization due to the dismantling of tacit informal networks built up over time.
\end{abstract}

Keywords: Data warehouse, organizational culture, employee alienation, business intelligence, silo effect, communication, qualitative, case study, technology acceptance

\section{INTRODUCTION}

The transition to large data warehouses for organizations has been an ongoing theme for several years. Organizations have recently been attempting to gain competitive business advantages by using the data mining capacity of these warehouses to create business intelligence. While in many cases, the transition to these systems is relatively seamless, there are some issues that are created in this transition. The purpose of this study was to look at how mid-level managers within a for-profit university (academic deans) experienced the change from a silo based information management system to an integrated data warehouse system. In addition, it describes any cultural changes that occurred in the organization as a result of this change. The problem addressed by this study is that, for this group (mid-level education area managers at for-profit universities) there is little understanding of their experiences and expectations when major technological changes occur within their operational area. This study will attempt to add to the body of knowledge in this area. The data will be analyzed using qualitative research techniques.

The organization that was the focus of this study had previously used three separate data management systems for its three major functional areas, none of which were compatible with each other. One of the databases was Oracle based, another DB2, and the third was DOS based. Therefore, information was exchanged between functional areas by means of paper forms which were then independently entered into each database. The organization considered two strategies for addressing this issue. First, using Kimball's model, they proposed the idea of creating three separate data marts for each functional unit that could effectively communicate together. Subsequently however they decided to adopt Inmon's model and create a large data warehouse (known by the pseudonym '180') with accompanying integrated data marts supporting it. Therefore, the organization made a strategic decision to convert to a single data warehouse with integrated data marts feeding into the data warehouse. This decision was, in part, based on the organizations aggressive growth strategy. The impact of this decision on functional levels below senior management does not appear to have been a concern.

\section{LITERATURE REVIEW}

The literature review for this study focused on four key areas: data warehousing, organizational culture, the role of mid-level managers, and managing technological change. There is ample literature on the creation of data warehouses and the primary contributions of Inmon and Kimball. In 1990, William Inmon developed the concept of the data warehouse and was the first to coin the term. He advocated the development of large data warehouses in a top-down fashion [11, 12, 13]. In 1995, Ralph Kimball developed the data-mart concept, a denormalized usercentric model, which is a 'bottom-up' design [16]. The two authors form the dyad of understanding data warehouse development. The creation of data silos and their impact on efficiency in business is also well researched and documented. Most of the research focuses on how the 'silo effect' contributes to an inefficient exchange of 


\section{Issues in Information Systems}

Volume 13, Issue 1, pp. 17-24, 2012

information within an organization $[10,20,23,25,26]$. There are also numerous models on technology acceptance by workers, especially in areas of information technology $[19,21,28]$.

The impact of organizational culture is also an important aspect of this study, since it directly impacts the degree to which change is perceived within an organization. There are a number of important studies done on the impact of an organization's culture, especially in regards to how change is valued and processed within an organization $[1,9,18$, $22,29]$. The impact of technological change on an organization, which certainly is the case with a migration to a new data warehousing system, is also impacted by the culture of the organization [22].

The role of mid-level managers was also a critical component to this study, since this group was the focus of the case study. Therefore, understanding the roles and expectations of their position within an organizational structure was important. Ireland (1992) observed that mid-level managers were most indicative of the culture of any large organization and that their experiences can help understand and reinforce an organizations culture [14]. Dean, Beggs, \& Keane (2010) observed that mid-level managers are often placed in difficult positions within the organizational structure and may face ethical challenges when dealing with change [4]. The leadership role of midlevel managers in any organization can also impact their ability to adapt to and conceptualize change [14, 17].

An additional area reviewed was the impact of new technology on workers' motivations and satisfaction. Several studies on this issue raised important questions on how technologies, especially those that remove 'power' and 'decision making' from individuals can cause negative consequences for worker motivation and self-image [8, 15]. The impact of technological change on an organization can be profound. Reis \& Geller argue that it can fundamentally change the 'organization's DNA' [24]. In each of these areas, data warehousing, organizational culture, and technological change, the role of mid-level managers is a critical success factor for an organization. Therefore, understanding the impact of the transition phase of technological change on this group would provide insight into the overall effectiveness of change within an organization.

\section{RESEARCH METHODOLOGY}

\section{Rationale for using the case study method}

Case study methodology was selected for this study. A case study is an effective qualitative technique when the researcher has clearly identifiable cases within boundaries and seeks to provide an in-depth understanding of a case $[2,3]$. In this study, the boundaries are very clear and narrowly defined: the transitional experiences of four midlevel managers (academic deans) at a for-profit university during the migration from a silo based data management system to an integrated data warehouse. There are situations where the cases study methodology is appropriate. One of the important reasons to select a case study approach is that is provides a real situation with real people and events within an organization [5,7]. Additionally, a case study usually involves deep study and focuses on a special subject. It also is especially useful for discovering relationships and processes, which was a central feature of this study $[5,7,27]$. Therefore, in order to gain a greater understanding of this phenomenon, a case study is an appropriate methodology for the study [30]. This method involves the developed of detailed narratives of the participants' experiences with the phenomenon under study by using semi-structured in depth interviews. Participants are given great latitude in expanding upon their responses to these initial questions in order to gain depth and to maximize flexibility in responses [3].

\section{Participants}

The four mid-level managers that participated in this study were selected based on a convenience sample. These mid-level managers serve as Academic Deans at a for-profit university. They function primarily as mid-level managers and are responsible for business functions that one would associate with normal mid-level managers within any large organization, including budgeting, supervision, and communication within a structured bureaucracy. All four were reasonably close to the researcher geographically and all four had been involved in the transition from the silo based data management system to the integrated data warehouse system. The researcher contacted each of them via email and telephone in order to ask them to participate in the study. The first manager, 


\section{Issues in Information Systems}

Volume 13, Issue 1, pp. 17-24, 2012

George (all names used are pseudonyms) had been with the organization for over seven years and served as an academic dean for four years. He had begun his career as a full time faculty member with the organization. His academic background was in computers and mathematics, so his familiarity with databases was extensive. The second manager, David, had been with the organization less than one year, but had extensive industry experience using databases. The third, Paul, had been with the organization for six years and served as academic dean for three of those. His experience with using databases was limited to the silo based system that had been in operation in his department since he began with the organization. The fourth manager, Dyana, had been in her position for only six months and had little experience with the previous database management systems. She had come to the organization from another post secondary institution that used a large data warehouse and had extensive experience with the system. Her academic background was in the humanities.

\section{Data Collection}

In each case, a ninety minute, in-depth interview was conducted and the interview was recorded using software that captured audio. An interview protocol was developed. The protocol was semi structured in nature to allow for greater flexibility of responses from the participants [27]. The participants were asked to describe their experiences using the new data warehousing system. Follow up questions were asked to clarify issues and focus the interview. Follow up emails were also used to clarify statements and the participants were provided with transcripts of the interview in order to ensure that the researcher had adequately captured the essence of their experiences. The audio was then transcribed and analyzed for emerging themes. Case study research often involves the use of archival and other materials to gain appropriate depth [5]. The researcher was able to review training protocols and manuals associated with the transition to the data warehouse environment as well as email exchanges regarding the transition.

\section{Data Analysis}

Within-case analysis provided initial familiarity with the data. A second coder was used to ensure that emerging themes were coded properly and not biased in any way by the researcher. A challenge in this study was the creation of epoche, by which the researcher excludes any personal bias or judgment when reviewing the data. Since the researcher had also been involved in this migration and personally knew each of the participants, the use of a second coder of the data provided an additional safeguard against bias in the research [2,3]. Then cross-case analysis facilitated analysis beyond the preliminary impressions. Themes began to emerge as data was coded. Enumeration and categorization of data further contributed to analysis [6].

\section{RESULTS}

Three critical components emerged as important aspects of the transition to the data warehouse, according to the mid-level managers in this study: frustration with lack of access to useful data, an increase in inaccurate and mislabeled data leading to problems, and alienation from the organization. Further investigation revealed that for each of these components, three elements played a critical role: vested interest of the manager, communication and challenges. For example, with respect to frustration with lack of access to data, each of the subcomponents; vested interest, communication, and challenges impacted their overall levels of frustration with lack of access. These subcomponents were further evident in each of the other two themes and will be addressed in the study.

\section{Frustration with lack of access}

Vested interest of the manager. This was an important issue for each participant in the study. Prior to the integration of the data warehouse system, access was usually achieved through a tacit informal network that was learned over time within the organization. This network usually involved 'gatekeepers', such as administrative assistants, whose ability to circumvent lengthy and bureaucratic chains of command was highly valued by the participants. This enabled these mid-level managers to complete assigned tasks with minimal paperwork and expenditure of time. The new system completely removed this informal network, as all tasks were essentially funneled into the new system. Each of the participants, especially those with longer experience with the informal 


\section{Issues in Information Systems}

Volume 13, Issue 1, pp. 17-24, 2012

network, expressed concern and frustration with a system that "stops me from doing my job and makes me jump through nine hoops when it only used to take one phone call."

Another manager expressed concern that he felt 'devalued' under the new system. This sentiment was also conveyed indirectly by two other participants. One stated that, "I used to think that I was the one making decisions. I would gather information and use my best judgment. But now, judgment is irrelevant. You see, you just enter the data and wait for ['180'] to tell you what to do. It's demoralizing and degrading. It makes you feel as if they trust the machine and not the people."

Communication. This also emerged as a factor that impacted frustration. The new system openly discouraged the use of both email and phone as vehicles to gain information. All requests for information needed to be put into the system by 'creating cases', which were then run through an impersonal data management system. This slowed the process of task completion for each of the participants. One participant stated, "You can't talk to anyone anymore, or even send an email. If you do, they just say, well did it you put in the system yet? It's frustrating as heck because no one simply answers a simple question anymore without nine entries into the data warehouse. I'm all for documenting, but at my level, I need to get things done quickly and I need to talk.”

Several of the participants discussed making attempts to re-form some of the connections that they had during the silo-based organizational model with little success. A participant commented, "Even when I tried to call people and ask 'what to do' they would talk in hushed tones and say things like 'I really wish I could help you but the system says you need to follow the new protocols' Protocols? Whatever happened to helping people?" The lack of ready access to information that they used to gain through informal networks served as a consistent concern for this group.

Challenges. This was another important factor for the participants. Challenges included a lack of training in some very specific functional areas that were critical to their roles, as well as a general lack of expectation of positive outcomes from using the system. Another challenge expressed by three of the participants specifically was that they felt devalued. Information that they used to be able to access readily was now only available to their superiors, even though they believed it was essential to optimal performance of their management functions.

One consistent theme for each participant was an inability to get information that was essential for some of the reports they were required to complete. One manager expressed great frustration with this situation, "I used to do the daily 'student at risk' report by culling the data from our system. But the new system restricts what kind of information I can get and I can't get accurate data to do the report. So the regional dean complains that my reports aren't catching all the information they should. So now, I just make the data up and everyone seems happy again." Another commented that when she complained and asked for greater 'permissions' to gain access to the data warehouse, she was informed that only regional deans had that access now. She would have to speak with her regional dean to get the information. Each of the managers interviewed expressed concern that they were being 'left out of the loop', regarding critical access to information to effectively perform their functions.

\section{Increases in inaccurate and mislabeled data}

Vested interest of the manager. Each of the managers believed that the old system, while somewhat archaic (it was DOS based) functioned effectively for their particular functional area. One of the issues that emerged was when the three silo data bases were merged; there were numerous errors and overlapping data. Concern for this was especially strong in areas that directly impacted the managers. One academic dean effectively summarized the problem in this area, "The real problem is that if you have a student with a full name in the admissions data base and then a middle initial in ours, they show up as separate students. It's insane, and when I run reports it looks as if I have issues with hundreds of students. The regional dean calls and complains and I tell them my hands are tied because I cannot change data in the system."

Communication. Dealing with inaccuracies in the database caused concerns with each of the managers. All four had several anecdotal stories about who they could talk to about inaccurate data and who exactly was permitted to change data in the system. A major issue in this area was a lack of any coordinated system for solving issues of 


\section{Issues in Information Systems}

Volume 13, Issue 1, pp. 17-24, 2012

inaccurate data. The system openly discouraged direct phone and email contact and insisted on using the database itself to solve the inaccurate database entries. The destruction of the informal networks within the organization was a consistent issue raised by the participants.

Another issue for these participants was that they felt powerless to effect any changes to inaccurate data. All of them expressed concern that their perceived value and prestige of their position had been diminished. One participant stated, "You can't talk to anyone about switching names in [180]. Everyone you try to talk to says, 'just enter a case in [180] and someone will take care of it.' But you never seem to know if your issue is ever solved. They make you go begging to the machine in order to change data that used to be corrected with a phone call. Now, it's enter the data and wait because apparently I can't be trusted to simply change something that I know is wrong."

Challenges. The culture of the organization played a significant role in this area for each of the participants. The upper administration had made it very clear throughout the organization that acceptance of the new data warehouse system was essential for all functional areas. The social culture of the organization is one that is not conducive to constructive feedback, especially when it comes from positions below upper management. One participant's observation serves as an exemplar for the group, "If you try to tell anyone the system is full of errors, then you're not a 'team player.' We all know what happens here to anyone who is 'not on board.' They just disappear. It's like working for the mafia, bodies disappear, you don't ask why, you just keep your head down and hope you're not next."

Another challenge specifically mentioned by three of the participants dealt with several specific reports that involved data that had been collected from each of three previous silo data marts and then uploaded into the new system. This report was a daily generated list of potential students for classes, upon which all future class scheduling was based. Overlapping data names and misspellings in one database were not corrected and this caused numerous issues for all managers according to the participants. Direct efforts on the part of two participants to effect a change in this area were met with skepticism and outright disdain according to the participants. One remarked, "When I called the regional dean about all the errors caused by the redundancy of data in the new system, I was basically told not to 'rock the boat' and to give IT time to work out the bugs. Well, they had already pilot tested this thing for six month and clearly knew of the shortcomings of the thing and they basically told me to shut up and deal with it. So I wrote my daily reports knowing full well the information in them was basically worthless."

\section{Alienation from the organization}

Vested interests of the managers. Each of the managers expressed that the new data warehouse system had greatly reduced their interactions with other members of the organization. The level of alienation varied according to the level of their vested interest in the organization. Two expressed specifically that they really enjoyed working for the organization and especially liked the network of friends they had developed via the informal network that they previously used to get information. Since the organization is geographically dispersed throughout the United States, those that especially valued the relationship aspects of their jobs expressed the greatest amount of concern in this area. One participant stated, "I like the people here and I liked the fact that, even though I am at a rather remote campus, help and advice were only a phone call away. I liked talking to them, since there are only a few people here on campus. Now, everything goes into the 'system'. No one here talks to anyone and if you do call, they seem nervous that you are trying to talk to them instead of just bowing before the great data warehouse which has replaced people."

These sentiments were echoed by the other participants. One person stated that she initially had sincere appreciation for the organization, its mission, and especially the way it handled people. But the change to the data warehouse, for her, signified a major shift in policy, away from informal communication to much greater standardization. Several participants commented that, they began their careers with expectations of a long association with the organization. However, recent trends away from a more interpersonal experience have caused them to withdraw from the organizational commitment they felt when they first started in their positions. 


\section{Issues in Information Systems}

Volume 13, Issue 1, pp. 17-24, 2012

Communication. Again, this was a central issue for each of the participants. Three expressed a feeling of increased 'loneliness' in their offices because email and telephone communications are now discouraged. This led several of the participants to describe how the company seemed more monolithic and without any real 'personality' or culture. One noted, "I don't feel like I'm part of any group any more. I'm here alone and all I do is serve this stupid data warehouse. I guess top managers may get some use from it, but all it does at our level is turn us from thinking and feeling managers into data entry clerks. I'm way too educated for that. If that's all they want from an academic dean, they should hire someone else. I don't make decisions anymore, I don't communicate with colleagues anymore, I just wait for [180] to 'tell' me what to do." Another participant commented, "We used to be all about people. People mattered here. You know how we knew that? We talked to each other. You can't care about other people in the organization if you never speak to them. It's a robotic culture now."

The increase in alienation seemed to be a very impactful issue for each of the participants and the words they used in describing this feeling were powerful. They used terms such as 'lonely', 'isolated', and 'discouraged.' All of the participants were concerned about working within a system that seemed less personal and more focused solely on using the new data warehouse as the repository for all insights and analysis. One participant summed up his feelings of alienation thusly, "They used to ask me for my input and I felt like a valued member of the team. I mattered. Now I just input data and someone else, I assume, makes decisions. I don't feel valued for being 'me' anymore; I just input what I know in the system. That way, I guess, for them they capture my expertise forever, even after I leave. Now, I guess that's all well and good to a point, but I bet a lot more people will actually leave sooner than they thought they were when they joined this organization."

Challenges. Each manager discussed how difficult it was to try to form new informal networks, since the new data warehouse system had fully taken over that function. The organization was focusing on making certain that all communication was centered in the data warehouse. Several participants expressed doubt about their long term future with the organization. This was not entirely based on the impact of the data warehouse, but each said it decreased their overall satisfaction with their jobs. One participant exemplified the sentiments of the group when she stated, "We really are just cogs in a machine here now. It did not used to be like that, but you can just feel how cold and corporate things are, and this [180] system is endemic of that movement. They have focused more on process than people. The machines have won and there does not seem to be enough room for human beings around here anymore. If I get a chance to get another job with another company, I will seriously consider it."

Each participant also discussed how motivation and morale had not increased very much, if at all, after the migration had been completed. Two of the participants expressed frustration that, after the transition was completed, 'it never really got any better." Three of the participants stated that they felt 'distant' from the organization and were worried that the trend would continue. The informal communication network also acted as a kind of 'support system' that they could rely on when they needed information. It was now gone.

\section{FINDINGS \& CONCLUSIONS}

Reflection on the cross case analysis of these cases, involving mid-level managers as they transition from a silo based data management system to an integrated data warehouse environment, yielded some surprising insights. The managers that participated in this study experienced an overall decrease in job satisfaction. This began during the transition phase, but it has not been completely recovered since the new system became operational more than a year ago. In fact, one of the participants stated that the new data warehouse system, which he termed 'completely dehumanizing', has led him to consider going back to teaching full time. Another key insight was the emergent themes of vested interest, inaccurate data, and alienation.

Of the three major themes discussed in this case study, alienation seemed to be the most surprising factor. One of the major advantages of removing silo based information systems is that the data becomes fully integrated. Everyone has greater access to information across departmental lines. These advantages may be realized by upper level managers, who can now use data mining and other techniques to increase the business intelligence of the organization. However, at mid-level positions, these advantages seem to be only partly realized, if at all. Silos are also supposed to inhibit communication across functional areas. But in these cases, the culture of the organization 


\section{Issues in Information Systems}

Volume 13, Issue 1, pp. 17-24, 2012

had already adapted to overcome this. The development of tacit informal information networks, often based on years of developing personal relationships with people in other functional areas, had previously worked well. A key take away from this research is that these participants placed great value on the interpersonal relationships that these networks facilitated. Once removed, only a very cold and impersonal data warehouse was available for these managers, whose coping mechanisms had effectively been removed.

It also seems readily apparent that few mid-level managers were involved in the decision making process to adopt this new data warehouse system. While all the managers stated they received adequate training for the system, they each expressed concern during the training about many of the major themes that emerged in this study. One said, "It was obvious from the first day what some of the big issues where, but no one wanted to hear what we had to say." While it is certainly acceptable for senior level managers to make decisions on new data management systems, the lack of input from other functional groups impacted by the system might have lessened some of the major transitional issues faced by these participants.

As more and more, and even smaller companies are adopting the use of data warehouses to increase business intelligence, this research suggests that companies should pay closer attention to the human side of the equation. It appears that for some mid level managers, especially those that work in geographically separate communities, that isolation from the overall group culture can cause a sense of isolation and alienation, which can be exacerbated by a system that restricts their access to a critical factor that influences overall job satisfaction, increased ability to interact with other employees in order to solve problems and make decisions.

\section{FUTURE RESEARCH}

Another aspect of interest that was beyond the scope of this study would be the morale impact on organizational members that were previously parts of these tacit informal networks that flourished under the data silo system. Some workers with lower level job titles and levels of education within the organization held tremendous prestige and power because they served as 'gatekeepers' and sellers or brokers of knowledge in these tacit knowledge markets that developed as an operational outcome of the silo system. Administrative assistants and IT workers with tacit knowledge of the system were held in high regard by many middle managers because they could work around or circumvent the limitations of the silo systems. One of the participants commented that, "the other day I actually ran into that lady that used to do the entire grade change procedures. She used to always seem so eager to help everyone and always had a smile on her face. Now, she looks like we all do; zombies in this big machine." It could prove interesting to understand the impact that the dismantling of these informal networks had on administrative staff that were at the center of these networks prior to the adoption of the data warehouse system.

Additionally, further research into what went wrong in this migration for these managers might prove instructive in avoiding these issues with future technological changes within the organization. The alienation that resulted from the adoption of a system designed to remove most 'decision making' functions from these managers was a key issue found in this study. Further understanding of the impact this played on overall performance and satisfaction for these managers could help minimize the alienation they felt and allow organizations to develop fully comprehensive technology migration strategies that encompass the human element to a greater degree than happened in this case [15]. One of the participants closed with this comment that summarizes the feelings of these managers in regard to how they felt about the entire transition, "We were made to feel like insignificant players in the company. We used to feel prestige about our jobs, we used to feel connected to the organization. I get it that change is an important part of the mission, I know that. I think, in the end, what really we were hoping for was to feel that we mattered during the change, that would have made all the difference in the world to me."

\section{REFERENCES}

1. Champoux, J. E. (2011). Organizational behavior : Integrating individuals, groups, and organizations.

Routledge.

2. Creswell, J. W., \& Miller, D. L. (2000). Determining validity in qualitative inquiry. Theory Into Practice, 39(3), 124. 


\section{Issues in Information Systems}

Volume 13, Issue 1, pp. 17-24, 2012

3. Creswell, J. W. (1998). Qualitative inquiry and research design: choosing among five traditions. Thousand Oaks, CA: Sage.

4. Dean, K., Beggs, J., \& Keane, T. (2010). Mid-level managers, organizational context, and (un)ethical encounters. Journal of Business Ethics, 97(1), 51-69.

5. Denzin, N. K. \& Lincoln, Y. S. (2005) Introduction: The discipline and practice of qualitative research, in: N. K. Denzin \& Y. S. Lincoln (Eds) Handbook of qualitative research (3rd edn) (Thousand Oaks, CA, Sage Publications).

6. Eisenhardt, K. M. (1989). Building theories from case study research. Academy of Management Review, 14, 532-550.

7. Frost, N. A., Holt, A, Shinebourne, P, Esin, C., Nolas, S, Mehdizadeh, L. \& Brooks-Gordon, B. (2011). Collective Findings, Individual Interpretations: An illustration of a pluralistic approach to qualitative data analysis. Qualitative Research in Psychology, 8(1), 93-113.

8. Gardell, B. (1976). Technology, alienation and mental health. Acta Sociologica (Taylor \& Francis Ltd), 19(1), 83-93.

9. Gaynor, G. H. (2004). What every new manager needs to know: Making a successful transition to management. AMACOM.

10. Help! I'm siloed, and I can't get out!. (2007). Velocity, 9(3), 6.

11. Inmon, W. H. (2002). Building the data warehouse (3rd ed). New York: John Wiley \& Sons.

12. Inmon, W. H. (2004) Measuring success. DM Review, 14(9), 66.

13. Inmon W. H. (2005) A brief history of architecture. DM Review, 15(4), 48-50.

14. Ireland, R. (1992). Corporate culture best conveyed by mid-level managers. Baylor Business Review, 10(1), 18.

15. Katrinli, A., Penbek, S., Günerergin, M., \& Zaptcioglu, D. (2011). Toward an alienated workforce: The impact of technology on the development of an alienated workforce. Review of Business Research, 11(2), 178-182.

16. Kimball, R., \& Ross, M. (2002). The data warehouse toolkit: the complete guide to dimensional modeling (2nd ed.) New York: John Wiley \& Sons.

17. Kowske, B. J., \& Anthony, K. (2007). Towards defining leadership competence around the world: What midlevel managers need to know in twelve countries. Human Resource Development International, 10(1), 21-41.

18. Middleton, J. (2002). Organizational behavior. Capstone Publishing.

19. Pasaoglu, D. (2011). Analysis of ERP usage with technology acceptance model. Global Business \& Management Research, 3(2), 157-165.

20. Phyper, J., \& Leavoy, P. (2010). Is an integrated management system right for your business?. Quality, 49(6), 38-41.

21. Polites, G. L., \& Karahanna, E. (2012). Shackled to the status quo: the inhibiting effects of incumbent system habit, switching costs, and inertia on new system acceptance. MIS Quarterly, 36(1), 21-A.

22. Rahmati, V., Darouian, S., \& Ahmadinia, H. (2012). A Review on effect of culture, structure, technology and behavior on organizations. Australian Journal of Basic \& Applied Sciences, 6(3), 128-135.

23. Reilly, T. (2011). Tearing down silos. Official Board Markets, 87(17), 13.

24. Reis, M., \& Geller, J. B. (2010). A manager's guide to human behavior. AMACOM.

25. Singh, A. , Upadhyay, D. C., \& Yadav, H. (2011). The analytical data warehouse: a sustainable approach for empowering institutional decision making. International Journal of Engineering Science \& Technology, 3(7), 6049-6057.

26. Stone, F. (2004). Deconstructing silos and supporting collaboration. Employment Relations Today (Wiley), 31(1), 11-18.

27. Toloie-Eshlaghy, A., Chitsaz, S., Karimian, L., \& Charkhchi, R. (2011). A classification of qualitative research methods. Research Journal of International Studies, 20106-123.

28. Weiyin, H., Thong, J. L., Chasalow, L. C., \& Dhillon, G. (2011). User acceptance of agile information systems: a model and empirical test. Journal Of Management Information Systems, 28(1), 235-272.

29. Wilson, F. M. (1999). Organizational behaviour : A critical introduction. Oxford University.

30. Yin, R. K. (1994). Case study research design and methods. Thousand Oaks, CA: Sage. 